\title{
Prevalence and Risk Factors of Hypertension Among Male Police Personnel in Urban Puducherry, India
}

\author{
Ganesh KS, ${ }^{1}$ Naresh AGV, ${ }^{1}$ Bammigatti C ${ }^{2}$
}

${ }^{1}$ Department of Community Medicine

${ }^{2}$ Department of General Medicine

Jawaharlal Institute of Postgraduate Medical Education and Research (JIPMER)

Puducherry, India

\section{Corresponding Author}

Ganesh Kumar S

Department of Community Medicine

Jawaharlal Institute of Postgraduate Medical Education and Research (JIPMER)

Puducherry, India

E-mail: sssgan@yahoo.com

\section{Citation}

Ganesh KS, Naresh AGV, Bammigatti C. Prevalence and Risk Factors of Hypertension Among Male Police Personnel in Urban Puducherry, India. Kathmandu Univ Med J 2014;48(4):242-6.

\section{ABSTRACT}

\section{Background}

Hypertension is an important health issue among high risk occupation groups like police personnel.

\section{Objective}

To assess the prevalence and risk factors of hypertension among male police personnel.

\section{Method}

This cross sectional study was conducted among male police personnel residing in urban Puducherry, India. Data on blood pressure (BP), anthropometric measurements, demographic factors, smoking, alcohol intake, physical activity, stress level, obesity and dietary factors were collected by interview technique using a standard questionnaire.

\section{Result}

About 296 police personnel were participated. Most of them belonged to the age group of 25-39 years (68\%). The prevalence of pre-hypertension and hypertension was $37.8 \%$ and $34.5 \%$ respectively. Among those with hypertension, $56.86 \%$ (58/102) were known hypertensives and 43.13\% (44/102) were newly diagnosed. Age group of $50-59$ years $(A O R=8.472$ ) and $40-49$ years $(A O R=8.15)$, currently using alcohol ( $A O R=1.797)$, less than 7 servings of fruits in a week $(A O R=3.228)$, moderate stress level $(A O R=2.374)$ and waist circumference more than $90 \mathrm{~cm}(A O R=4.937)$ were associated with higher prevalence of hypertension among police personnel.

\section{Conclusion}

Hypertension among Police personnel is comparatively higher than general population in this area. Reduction in alcohol use, increase in fruit servings along with other lifestyle modification measures may help in prevention and control of hypertension.

\section{KEY WORDS}

Hypertension, police personnel, risk factors, urban India 


\section{INTRODUCTION}

In India, the Coronary Heart Disease (CHD) rate is expected to rise in parallel with the increase in life expectancy secondary to increase in per capita income and declining infant mortality. ${ }^{1}$ Elevated blood pressure is one of the major risk factor for cardiovascular morbidity and mortality. Increased risk begins in the pre-hypertensive stage and increases further with higher blood pressure levels. ${ }^{2}$

Police personnel constitute a special occupational group with exposure to violence and stress at work, which directly and indirectly affects their health. ${ }^{3}$ A cohort study on Helsinki policemen found coronary heart disease as a major cause of mortality among policemen. ${ }^{4}$ Obesity, dietary factors, smoking, alcohol use, exposure to stress at work and lack of physical activity were important factors associated with hypertension. Very few studies were conducted with regard to this among police personnel in India. ${ }^{3,5}$ With this background, the present study was conducted to assess the prevalence and certain risk factors of hypertension among male police personnel in urban Puducherry, India.

\section{METHODS}

\section{Setting}

This cross sectional study was conducted from April 2013 to September 2013 among male police personnel residing in police quarters of Dhanvantri Nagar, urban Puducherry, India.

\section{Sample size estimation and Sampling technique}

By considering prevalence of hypertension among police personnel as $22.5 \%^{5}$ and precision at $25 \%$ level, the minimum sample size was found to be 231 . By adding $10 \%$ non-response error, total sample size became 254. However, we followed convenient sampling method and decided to include all the 396 male police personnel residing in the police quarters in Dhanvantari Nagar, Puducherry.

\section{Ethical issues}

Approval was obtained from the Institution Ethics Committee before commencement of the study. Due written permission was obtained from the Inspector General of Police before initiating the study. Written informed consent was taken from the subjects.

\section{Study tools and method of data collection}

BP was measured by using a mercury sphygmomanometer of appropriate cuff size, after 5 minutes of rest with subjects in sitting position, feet relaxed on floor and arm supported at chest level. ${ }^{6}$ Hypertension is defined as a systolic BP of $140 \mathrm{mmHg}$ or above or diastolic BP of $90 \mathrm{mmHg}$ or above, in a minimum of 2 readings at least 5 minutes apart. The subjects were classified as Normal, Pre-hypertensive or Hypertensive according to JNC VII criteria. ${ }^{7,8}$ Known hypertensives diagnosed previously by registered medical practitioner were considered as hypertensive which was confirmed either by history of taking treatment or based on prescription slips. Thus prevalent hypertension cases were also included as known hypertensives. Pre-hypertensives were those with systolic BP of $120-139 \mathrm{mmHg}$ or diastolic BP of $80-89 \mathrm{mmHg}$.

Data was collected by the investigator in their house. A structured questionnaire was prepared which included questions on diet, smoking, alcohol intake, physical activity and other self-reported co-morbid conditions. Part of the questionnaire included core and /or expanded items of WHOSTEPS instrument and it was pre-tested. ${ }^{9}$ Consumption of any junk food which included deep fried snacks, pizzas, burgers, chips and cold drinks in the preceding week was considered to assess the junk food consumption. Stress was assessed by Cohen's Perceived Stress scale. ${ }^{10}$ Height was measured using a non-stretchable measuring tape, with an accuracy of $0.1 \mathrm{~cm}$, standing against a wall bare foot, and weight was measured using an electronic weighing scale with an error of $\pm 0.1 \mathrm{~kg}$. The complete process took about an hour for a subject.

\section{Statistical analysis}

The collected data was entered in Statistical Package for Social Sciences version 19 for windows (SPSS v.19). It was analyzed by using univariate and multivariate analysis. ' $p$ ' value of less than 0.05 was considered as statistically significant.

\section{RESULTS}

The data was collected from 296 male police personnel with a response rate of $75 \%$. Most of them belonged to the age group of $25-39$ years (68\%). The prevalence of pre-hypertension and hypertension was $37.8 \%$ and $34.5 \%$ respectively. Among those with hypertension, $56.86 \%$ (58/102) were known hypertensives and $43.13 \%$ (44/102) were newly diagnosed [Table 1]. The proportion of those with associated risk factors were overweight and obesity (54.4\%), smoking $(21.6 \%)$, alcohol use $(50.3 \%)$, very high level of perceived stress (51\%) and diabetes (10.1\%).

Table 1. Prevalence of Hypertension among Police personnel in the study population $(\mathrm{N}=\mathbf{2 9 6})$

\begin{tabular}{|lcl|}
\hline Variables & $\begin{array}{c}\text { Number of } \\
\text { subjects }\end{array}$ & $\begin{array}{l}\text { Percentage }(95 \% \\
\text { Confidence Interval) }\end{array}$ \\
\hline $\begin{array}{l}\text { Normal } \\
\text { (SBP<120 and DBP<80) }\end{array}$ & 82 & $27.7 \%(22.6-32.8)$ \\
\hline $\begin{array}{l}\text { Pre hypertensive } \\
\text { (SBP 120-139 or DBP 80-89) }\end{array}$ & 112 & $37.8 \%(32.28-43.32)$ \\
\hline $\begin{array}{l}\text { Hypertensive Grade I } \\
\text { (SBP 140-159 or DBP 90-99) }\end{array}$ & 42 & $14.2 \%(10.22-18.18)$ \\
\hline $\begin{array}{l}\text { Hypertensive Grade II } \\
\text { (SBP } \geq 160 \text { or DBP } \geq 100)\end{array}$ & 2 & $0.7 \%(-0.25-1.65)$ \\
\hline Known Hypertensives & 58 & $19.6 \%$
\end{tabular}


Table 2. Prevalence of hypertension according to risk factors

( $N=296)$ :

\begin{tabular}{|c|c|c|c|}
\hline Variable & $\begin{array}{c}\text { No. of } \\
\text { Subjects }\end{array}$ & $\begin{array}{l}\text { Subjects with } \\
\text { Hypertension }\end{array}$ & $\chi 2, p$ value \\
\hline \multicolumn{4}{|l|}{ Age } \\
\hline $25-39$ & 202 & $56(27.7)$ & \multirow{3}{*}{$\begin{array}{l}23.504 \\
0.000^{*}\end{array}$} \\
\hline $40-49$ & 56 & $20(35.7)$ & \\
\hline $50-59$ & 38 & $26(68.4)$ & \\
\hline
\end{tabular}

Designation

$\begin{array}{lccc}\text { Home Guard } & 26 & 6(23.1) & \\ \text { Police Constable } & 166 & 52(31.3) & 6.90,0.075 \\ \text { Head Constable } & 82 & 32(39.0) & \\ \text { Sub-Inspector } & 22 & 12(54.5) & \end{array}$

Vigorous Physical Activity

$\begin{array}{lccc}\text { Nil } & 226 & 74(32.7) & \\ <60 \text { minutes } & 33 & 12(36.4) & 1.612,0.447 \\ \geq 60 \text { minutes } & 37 & 16(43.2) & \end{array}$

Moderate Physical Activity

$\begin{array}{llll}\text { Nil } & 208 & 66(31.7) & \\ <120 \text { minutes } & 78 & 32(41.0) & 2.311,0.315 \\ \geq 120 \text { minutes } & 10 & 4(40.0) & \end{array}$

Current Smoker

$\begin{array}{lll}\text { Yes } & 64 & 28(43.8) \\ \end{array}$

No

$23274(31.9)$

Current Alcohol Use

$\begin{array}{ccll}\text { Yes } & 149 & 60(40.27) & \begin{array}{l}4.483 \\ \text { No }\end{array} \\ \text { No } & 147 & 42(28.57) & \\ \begin{array}{l}\text { Added Extra Salt While } \\ \text { Dining }\end{array} & & & \\ \text { Yes } & 70 & 28(40) & \\ \text { No } & 224 & 72(32.1) & 1.467,0.226\end{array}$

Consumption of foods with high salt content

\begin{tabular}{|c|c|c|c|}
\hline Yes & 186 & $58(31.2)$ & \multirow{2}{*}{$2.379,0.123$} \\
\hline No & 110 & $44(40)$ & \\
\hline \multicolumn{4}{|c|}{ Consumption of junk food } \\
\hline Yes & 163 & $48(29.5)$ & \multirow{2}{*}{$4.034,0.045$} \\
\hline No & 133 & $54(40.6)$ & \\
\hline
\end{tabular}

No. of Fruits Servings/week

$\begin{array}{rcll}<7 & 225 & 86(38.2) & 5.880 \\ \geq 7 & 71 & 16(22.5) & , 0.015^{*} \\ \text { Diabetes } & & & \\ \text { Yes } & 30 & 16(53.3) & 5.265 \\ \text { No } & 266 & 86(32.3) & , 0.022^{*}\end{array}$

\section{Kidney Disease}

$\begin{array}{ccll}\text { Yes } & 8 & 2(29.0) & 0.326,0.568 \\ \text { No } & 288 & 100(34.7) & \end{array}$

Perceived Stress

$\begin{array}{lcll}\text { Low } & 14 & 4(28.6) & \\ \text { Moderate } & 34 & 9(26.5) & 10.161 \\ \text { High } & 97 & 24(24.7) & , 0.017^{*} \\ \text { Very high } & 151 & 65(43.0) & \end{array}$

BMI(in kg/m2)

$\begin{array}{cccc}<25 & 135 & 34(25.2) & \\ 25-29.9 & 137 & 54(39.4) & 12.688 \\ \geq 30 & 24 & 14(58.3) & \\ \quad 0.002 * \\ \text { Waist Circumference(in cm) } & & & \\ & & & \\ <90 & 231 & 60(25.9) & \\ \geq 90 & & & 33.537 \\ & 65 & 42(64.6) & , 0.000^{*}\end{array}$

*P value less than 0.05 is considered as significant.

Table 3. Correlates of hypertension: Multiple logistic regression analysis

\begin{tabular}{|c|c|c|}
\hline Variables & Adjusted OR (95\% C.I.) & $P$ value \\
\hline \multicolumn{3}{|l|}{ Age } \\
\hline $50-59$ & $8.472(3.200-22.431)$ & $0.000 *$ \\
\hline $40-49$ & $8.150(2.730-24.320)$ & $0.000^{*}$ \\
\hline $25-39$ & - & \\
\hline \multicolumn{3}{|c|}{ Current Alcohol Use } \\
\hline Yes & $1.797(1.00-3.239)$ & 0.05 \\
\hline No & - & \\
\hline \multicolumn{3}{|c|}{ Consumption of Junk Food } \\
\hline Yes & $0.586(0.328-1.048)$ & 0.071 \\
\hline No & - & \\
\hline \multicolumn{3}{|c|}{$\begin{array}{l}\text { Number of fruit servings/ } \\
\text { week }\end{array}$} \\
\hline$<7$ & $3.228(1.512-6.890)$ & $0.002 *$ \\
\hline$\geq 7$ & - & \\
\hline \multicolumn{3}{|l|}{ Diabetes } \\
\hline Yes & $0.638(0.231-1.761)$ & 0.386 \\
\hline No & - & \\
\hline \multicolumn{3}{|c|}{ Perceived Stress } \\
\hline Very High & $1.484(0.354-6.213)$ & 0.589 \\
\hline High & $2.215(0.846-0.5 .801)$ & 0.105 \\
\hline Moderate & $2.374(1.243-4.535)$ & $0.009 *$ \\
\hline Mild & - & \\
\hline \multicolumn{3}{|c|}{ BMI(in kg/m2) } \\
\hline$\geq 30$ & $1.745(0.504-6.048)$ & 0.380 \\
\hline $25-29.9$ & $1.228(0.392-3.847)$ & 0.724 \\
\hline$<25$ & - & \\
\hline \multicolumn{3}{|c|}{ Waist Circumference(in cm) } \\
\hline$\geq 90$ & $4.937(2.201-11.075)$ & $0.000 *$ \\
\hline$<90$ & - & \\
\hline
\end{tabular}

*P value less than 0.05 is considered as significant.

It was shown that age was significantly associated with hypertension. Hypertension prevalence was found to increase with age. The prevalence was also found to be more among Sub inspector grade compared to other grades. Alcohol use, lesser fruit servings, diabetes and higher perceived stress were significantly associated with hypertension. Similarly higher Body Mass Index and waist circumference was associated with higher prevalence of hypertension [Table 2]. Multiple Logistic 
Regression Analysis showed that age group of 50-59 years ( $A O R=8.472$ ) and 40-49 years ( $A O R=8.15)$, currently using alcohol (AOR=1.797), less than 7 servings of fruits in a week ( $A O R=3.228)$, moderate stress level $(A O R=2.374)$ and waist circumference more than $90 \mathrm{~cm}(A O R=4.937)$ were associated with higher prevalence rate of hypertension [Table 3].

Among subjects who were previously diagnosed with hypertension (58), 55\% (32) were on regular antihypertensive medications, while others were not taking the prescribed drugs regularly with missing at least 2 doses in the preceding month. Life style modification was advised for $72 \%(42)$ of them along with the treatment.

\section{DISCUSSION}

We hypothesized to assess the prevalence of hypertension and its associated risk factors among male police personnel in Puducherry region of India. The prevalence of hypertension was $34.5 \%$ and associated risk factors were overweight and obesity (54.4\%), smoking (21.6\%), alcohol use $(50.3 \%)$, very high level of perceived stress $(51 \%)$ and diabetes (10.1\%); and were comparatively higher than the results of other studies. ${ }^{5,6}$ In a study in the year 2008 in the same place and same group of personnel in Pondicherry, India, the prevalence rate of hypertension was $30.5 \%{ }^{6}$ This study highlights the marginal increase in prevalence over a period of 5 years. But, its interpretation should be done cautiously because it may be over reported or under reported because of the cross sectional study nature, and there may be overlapping of some of earlier study subjects and difference in data collection process between the two studies. Among Bank employees in Puducherry, prevalence of hypertension was found to be $44.3 \%,{ }^{11}$ while Group C employees of JIPMER it was found to be $38.8 \%{ }^{12}$ A recent study in urban Tamil Nadu among the residents found the prevalence of hypertension as $31.5 \% .{ }^{13}$ Nagpur study found the prevalence rate of hypertension as $22.5 \% .^{5}$ In contrast a recent study in Kerala found the prevalence rate of hypertension to be $37.7 \% .^{3}$ In view of the above, the prevalence may be comparable or marginally higher than other risk groups or general population.

Our study in contrast to above studies showed some differences with respect to risk factors like proportion of overweight and obesity (54.4\% vs $43.08 \%)$, tobacco use ( $21.6 \%$ vs $54.42 \%$ ) and alcohol consumption (50.3\% vs $28.27 \%) .{ }^{5}$ Study done in Kerala had higher body mass index (65.6\%) while other risk factors like diabetes (7\%), smoking (10\%), and alcohol use (48\%) were comparatively lower than in our study. ${ }^{3}$

A study showed that cardiovascular risk among police personnel is higher compared to general population in India. This is because police had higher prevalence of cardio metabolic abnormalities and diabetes in comparison to general population. ${ }^{14}$

Alcohol consumption may influence the higher prevalence of risk factors for IHD in police officers. Potential mechanisms for this relationship include a direct pressor effect of alcohol on the vessel wall, sensitization of resistance vessels to pressor substances, stimulation of the sympathetic nervous system and increased production of adrenocorticoid hormones. ${ }^{15}$

\section{Limitations}

The study findings may not be generalizable to police officers of Puducherry since it lacks proper sampling technique and include only males. Single occasion BP measurement also may lead to misclassification bias. There may be subjective bias, and detailed dietary history, quantification of certain risk factors and biological parameters were not assessed due to feasibility constraints. Details on medications of those with previously diagnosed hypertensives were not assessed. The non-response rate was comparatively higher than expected.

\section{CONCLUSION}

Hypertension among police personnel is more in this area compared to general population. Reduction in alcohol use, increase in fruit servings along with other lifestyle modification measures may help in prevention and control of hypertension. The study gives valuable information regarding the present magnitude of hypertension and certain risk factors among this vulnerable group. This information can be utilized for introduction and implementation of appropriate interventional measures by the concerned authorities.

\section{REFERENCES}

1. Yusuf S, Reddy S, Ounpuu S, Anand S. Global burden of cardiovascular diseases: Part II: Variations in cardiovascular disease by specific ethnic groups and geographic regions and prevention strategies. Circulation 2001;104:2855-64.

2. Stefanos NK, Antonios JT, Chunbai Z, Elpidoforos SS. Blood Pressure in Fire-fighters, Police Personnel, and Other Emergency Responders. American Journal of Hypertension 2009; 22:11-20.

3. Thayyil J, Jayakrishnan TT, Raja M, Cherumanalil JM. Metabolic syndrome and other cardiovascular risk factors among police personnel. North Am J Med Sci 2012;4:630-5.

4. Pyorala M, Miettinen N, Laakso M, Pyorala K. Plasma insulin and all cause, cardiovascular and non-cardiovascular mortality in Helsinki policemen. Diabetes Care 2000; 23:1097-102.

5. Priyanka Rastogi. Diet and High Blood Pressure; 2005. (Accessed August 4, 2013, at http://sajprevcardiology.com/vol9/vol9_2/ highprevalenceofcoronaryheartdisease.htm)

6. Ramakrishnan J, Majgi SM, Premrajan KC, Lakshminarayanan S, Thangaraj S, Chinnakali P. High prevalence of cardiovascular risk factors among policemen in Puducherry, South India. J Cardiovasc Dis Res 2013;4:112-5. 
7. Thomas GP, John EH, Lawrence JA, Bonita EF, John G, Martha NH et al. Recommendations for Blood Pressure Measurement in Humans: $A$ Statement for Professionals from the Subcommittee of Professional and Public Education of the American Heart Association Council on High Blood Pressure Research. Hypertension 2005;45;142-161.

8. Chobanian AV, Bakris GL, Black HR, Cushman WC, Green LA, Izzo $J \mathrm{~L} J$ r, et al. The Seventh report of the joint national committee on prevention, detection, evaluation, and treatment of high blood pressure: the JNC 7 report. JAMA 2003;289:2560-72.

9. WHO STEP wise approach to chronic disease risk factor surveillance - Instrument v2.1. Accessed August 6, 2013, Available from: http:// www.who.int/chp/steps/riskfactor/en/.

10. Cohen S, Kamark T, Mermelstein R. A global measure of perceived stress. J Health Soc Behav 1983 ;24:385-96.

11. Ganesh Kumar S, Deivanai Sundaram N. Prevalence and risk factors of hypertension among bank employees in urban Puducherry, India. Int J Occup Environ Med 2014;5:94-100.
12. Ashwin K, Ghorpade AG, Kar SS, Kumar G. Cardiovascular Disease Risk Factor Profiling of Group C Employees in JIPMER, Puducherry. J Fam Med Prim Care 2014; 3:255-9.

13. Bhansali A, Dhandania VK, Deepa M, Anjana RM, Joshi SR, Joshi PP et al. Prevalence of and risk factors for hypertension in urban and rural India: the ICMR-INDIAB study. J Hum Hypertens 2014; doi: 10.1038/ jhh.2014.57. [Epub ahead of print]

14. Tharkar S, Kumpatla S, Muthukumaran P, Viswanathan V. High prevalence of metabolic syndrome and cardiovascular risk among police personnel compared to general population in India. J Assoc Physicians India 2008;56:845-9.

15. Shiozaki M, Miyai N, Morioka I, Utsumi M, Koike H, Arita M, et al. Assessment of the Risk of Ischemic Heart Disease and its Relevant Factors among Japanese Police Officers. Sangyo Eiseigaku Zasshi 2013; 55:115-24. 